Volume 6

\title{
The Impact of Nondiagnostic Information on Selection Decision Making: A Cautionary Note and Mitigation Strategies
}

\author{
Dev K. Dalal \\ University at Albany, State University of New York \\ Levi Sassaman \\ University at Albany, State University of New York \\ Xiaoyuan (Susan) Zhu \\ University of Kentucky
}

Follow this and additional works at: https://scholarworks.bgsu.edu/pad

Part of the Human Resources Management Commons, Industrial and Organizational Psychology Commons, and the Other Psychology Commons

How does access to this work benefit you? Let us know!

\section{Recommended Citation}

Dalal, Dev K.; Sassaman, Levi; and Zhu, Xiaoyuan (Susan) (2020) "The Impact of Nondiagnostic Information on Selection Decision Making: A Cautionary Note and Mitigation Strategies," Personnel Assessment and Decisions: Number 6 : Iss. 2 , Article 7.

DOI: https://doi.org/10.25035/pad.2020.02.007

Available at: https://scholarworks.bgsu.edu/pad/vol6/iss2/7

This Main Article is brought to you for free and open access by the Journals at ScholarWorks@BGSU. It has been accepted for inclusion in Personnel Assessment and Decisions by an authorized editor of ScholarWorks@BGSU. 


\title{
The Impact OF NONDIAGNOSTIC INFORMATION on Selection Decision Making: A Cautionary Note and Mitigation Strategies
}

\author{
Dev K. Dalal', Levi Sassaman ${ }^{1}$, and Xiaoyuan (Susan) Zhu ${ }^{2}$
}

\author{
1. University at Albany, State University of New York \\ 2. University of Kentucky
}

\begin{abstract}
KEYWORDS
nondiagnostic information, selection decision

making, dilution effect, misinformation
\end{abstract}

\begin{abstract}
Selection decision makers are inundated with information from which to make decisions about the suitability of a job candidate for a position. Although some of this information is relevant for making a high-quality decision (i.e., diagnostic information), much of the information is actually unrelated to the decision (i.e., nondiagnostic information). Although the deleterious effects of nondiagnostic information on selection decision making have been demonstrated, the prevalence and impact of this type of information is increasing, especially with recent advances in new selection methods used by employers. The purpose of this paper, therefore, is to caution selection decision makers, and/or those advising them, to the impact nondiagnostic information has on decisions. We also present different types and prevalence estimates of nondiagnostic information given the changes to the ways applicants are screened and selected. We conclude with suggestions for mitigating the use and/or negative impact of nondiagnostic information.
\end{abstract}

ABSTRACT

Decades of research has demonstrated the negative impact that providing nondiagnostic information to decision makers can have on decision-making performance (e.g., Carr et al., 2017; Nisbett et al., 1981; Waller \& Zimbelman, 2003; Zukier, 1982). This is particularly relevant for selection decision makers ${ }^{1}$ who have access to information from myriad sources (e.g., LinkedIn, Facebook, references) from which they can acquire job relevant (e.g., skills and abilities) as well as job irrelevant (e.g., fandom for a specific sport team) information about a candidate (Highhouse, 1997). In fact, the volume of information presented to selection decision makers has increased in recent years. As discussed in greater detail later, for instance, $70 \%$ of selection decision makers utilize social network sites to vet candidates. These websites contain, at times, a dizzying array of information about candidates, most of which is not valid for making selection decisions (see Brown \& Vaughn, 2011).

With some estimates of the cost of hiring in excess of $\$ 4,000$ per position to fill (Northon et al., 2016), it is costly to organizations to make bad hiring decisions (Fatemi,

1 We refer to selection decision makers as individuals, or technology, responsible for screening (e.g., recruiters; automated résumé screening) and/or selecting (e.g., hiring managers, human resources professionals) applicants for vacant job position.
2016). Understanding the potential pitfalls that can lead to bad hiring decision making is therefore important. Although research has consistently shown that using one's intuition results in poor-quality hires (Highhouse, 2008), individuals nevertheless put faith in their "expertise" and intuition to make selection decisions. Relying on one's intuition to make selection decisions, though, can often result in using irrelevant (i.e., nondiagnostic) information. The purpose of this paper is to highlight the negative impact nondiagnostic information can have on selection decision making, provide a picture of the prevalence of this type of information, and present methods for mitigating the impact of nondiagnostic information.

\section{Nature of Nondiagnostic Information}

Although individuals have various sources of information at their disposal when making decisions, ${ }^{2}$ decisions are most accurate when made using only relevant information given the specific context of the decision (Nisbett et al., 1981). In the language of the lens model (Hammond,

Corresponding author:

Dev K. Dalal

1400 Washington Ave SS-399

Albany, NY 12222

Email:dev.dalal@gmail.com 
1955) - a social judgment theory representation of how individuals use information when making a decision - high decision maker achievement (i.e., good decisions) results from utilizing only valid cues (i.e., diagnostic information) and ignoring invalid cues (i.e., nondiagnostic information; D. K. Dalal et al., 2010). A piece of information is diagnostic, then, to the extent that using it when making a decision results in a more accurate and/or better decision. As Tetlock and Boettger (1989) caution, "These diagnostic cues are, however, embedded in a bewildering array of irrelevant variables" (p. 388). Nondiagnostic information are these irrelevant variables. In other words, nondiagnostic information is information that is not related to the decision being made, and its use would result in worse quality decisions (i.e., reduced decision maker achievement; D. K. Dalal et al., 2010).

The detrimental impact of nondiagnostic information on social judgments (i.e., predictions of others) was demonstrated in a series of studies by Nisbett and colleagues (1981) and Zukier (1982; though see Troutman \& Shanteau [1977] for a demonstration in nonsocial judgment). In these studies, participants who received only diagnostic information made more accurate predictions of others than participants who received, in addition to the same diagnostic information, some nondiagnostic information. In particular, those in the latter condition tended to make less extreme (i.e., regressive) judgments than would be predicted had only the diagnostic information been used. For example, participants who were asked to predict the GPA of a student and given only a diagnostic information (i.e., "Robert studies 31 hours per week" p. 390, Tetlock \& Boettger, 1989) made more extreme (and accurate) GPA predictions than participants who received this information and nondiagnostic information (e.g., "Two months is the longest period of time Robert has dated one person," p. 390, Tetlock \& Boettger, 1989). Participants in this latter condition estimated that Robert would have a lower GPA, ostensibly because of his past dating history.

Naturally, the context of the decision matters in determining whether or not information is diagnostic: whereas information about someone (e.g., his/her dating history) may be diagnostic for one decision (e.g., is this someone I should date?), it is nondiagnostic for another (e.g., is this someone I should hire?) - stated differently, the validity of a cue is determined, in part, by the decision to be made (D. K. Dalal et al., 2010). Lab, field, and observational studies have since established the robustness of the dilution effect (Waller \& Zimbelman, 2003).

2 We acknowledge that the extant literature on the dilution effect investigates the impact of nondiagnostic information primarily on forming judgments. However, the results extend to decision making as well given the need to evaluate (i.e., judge) options before making a decision (R. S. Dalal et al., 2010).

\section{Nondiagnostic Information in Selection Decision Making}

Concerns about the allure of nondiagnostic information are particularly high in selection decision making because of the information-rich environment of hiring decisions bombarding decision makers with information about candidates (Highhouse, 1997); much of this information is irrelevant to predicting which candidate will perform the best on the job (Highhouse, 2008). Figure 1 presents the general steps in the hiring process and highlights some, though not an exhaustive list, of the different types of nondiagnostic information shown to impact decision making at each of the three decision points: (a) initial screening, (b) candidate assessments, and (c) finalist choice. Importantly, we note that the generality of the information presented in Figure 1 stems from the fact that selection methods (e.g., unstructured in-person interview or video-based interview) or the selection context (e.g., entry-level or management positions) will factor into the types of nondiagnostic information available at each stage. Nevertheless, by identifying the various types of nondiagnostic information and avenues, we highlight the different ways that irrelevant information can potentially negatively influence selection decision making.

For example, most selection decision makers would agree that a job applicant's gender is unlikely to be related to his/her capacity to perform the tasks of most jobs (i.e., gender is nondiagnostic), particularly for knowledge-based positions. As such, gender information should be discounted completely when making selection decisions from both an accuracy and legal perspective. Nevertheless, individuals perceived a female job candidate as less skilled and were less willing to hire her for a technology role than a male candidate (Rattan et al., 2019). In that decision making context, candidate gender has zero validity for that decision and is illegal to use in most countries ${ }^{3}$ - nevertheless, selection decision makers still used this information to judge suitability of the technology role. In sum, nondiagnostic information is present and can be utilized in hiring decision making situations, and the deleterious effects of nondiagnostic information on hirability judgments are exacerbated as the information becomes more compelling (Dalal et al., 2015).

Nondiagnostic information influences selection decision making because most selection decisions makers' "stubborn reliance" (p. 333) on their intuition to make

3 For example, Title VII of the Civil Rights Act of 1964 in the United States, the Canadian Human Rights Act of 1977, the Sex Discrimination Act of 1975 in the United Kingdom, and Article 13 of the 1999 Treaty of Amsterdam, agreed upon by all European Union nations, prohibit discrimination in employment based on applicants and/or employees gender. In short, these nations consider gender a protected class for selection decision making. 
FIGURE 1.

Hiring process steps with example assessments/screenings at each step. Nondiagnostic information can impact decision making at each of the three latter stages.

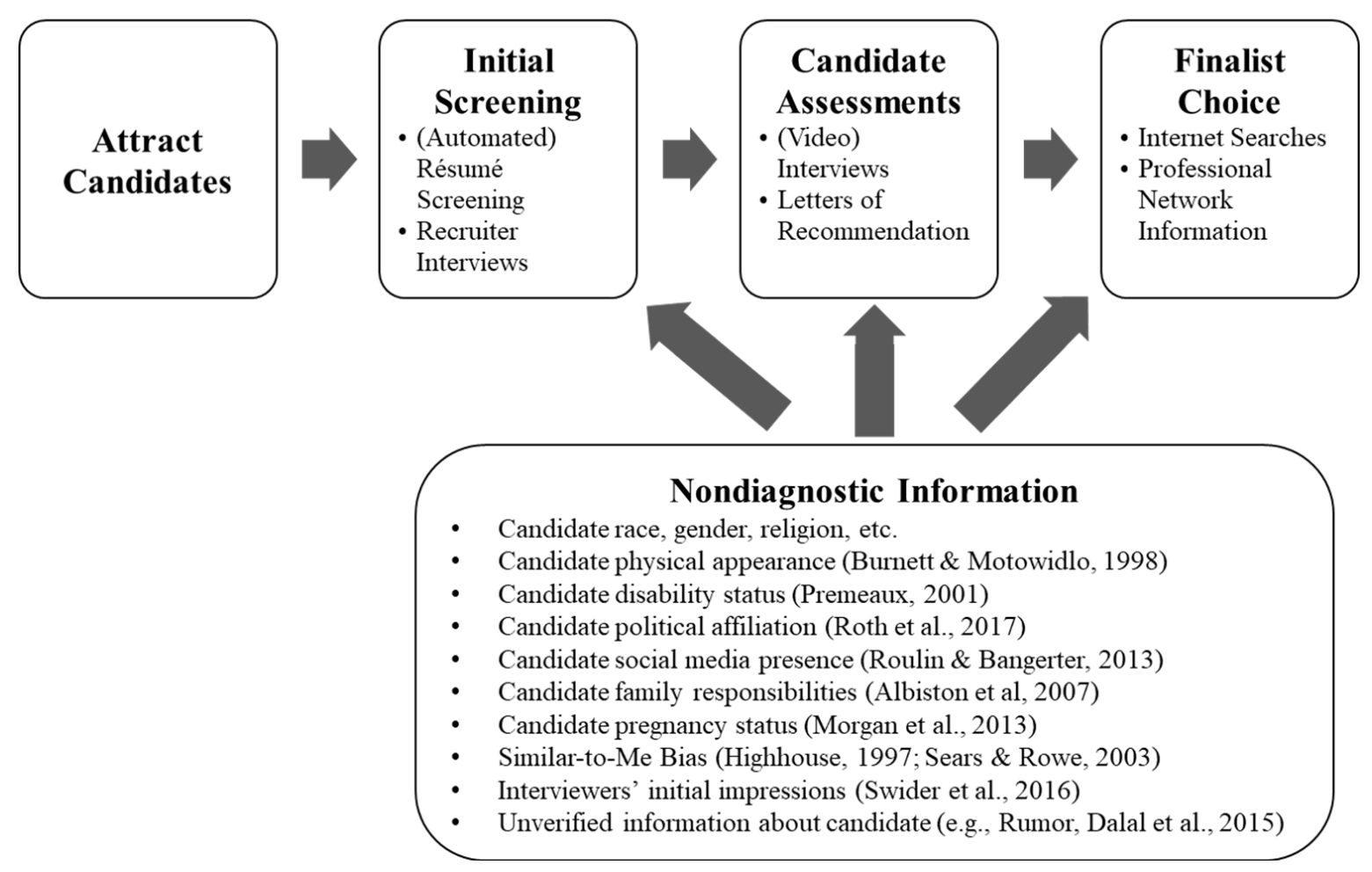

selection decisions (Highhouse, 2008). That is, rather than approach a selection decision in a logical and calculated manner, as advised by organizational scientists for decades, most selection decision makers prefer to rely on their implicit beliefs and gut feelings about candidates, believing their intuition and expertise allows them to gather a more nuanced understanding of a candidate that structured selection systems miss. Although Highhouse (2008) debunks many of the myths surrounding the efficacy of intuitive selection decision making, it nevertheless persists.

Selection decisions made with the use of intuition are suboptimal because using intuition tends to biases decisions (Larrick, 2004; Milkman et al., 2009; Soll et al., 2015). This bias results from a handful of different sources (Hastie \& Dawes, 2001). First, individuals generally tend to make judgments using only a few pieces of information. Second, individuals believe their decision making processes are more complex (i.e., involve nonlinear combination of information) than reality (i.e., linear models capture judgments accurately; see also Camerer \& Johnson, 1991). Third, individuals do not have accurate knowledge of how much they weigh information when making judgments. Fourth, different individuals use the same information in very dif- ferent ways; as such, there is little inter-individual agreement on judgments. Finally, confidence in the accuracy of one's judgment, though not actual accuracy, increases as the amount of irrelevant information increases.

The first and last conditions drive concerns about nondiagnostic information in selection decision: The availability of so much nondiagnostic information makes selection decision makers more confident in their decisions without a corresponding increase in accuracy because they rely on only a few pieces of the typically nondiagnostic information (Hastie \& Dawes, 2001). Intuitive decision making is characterized, in part, by expeditious and surface evaluation of information (Milkman et al., 2009; Soll et al., 2015). As such, the diagnostic value of information is unlikely to be sufficiently evaluated before use. When added to the concern that "more and more people are being tasked with making decisions that are likely to be biased because of the presence of too much information" (Milkman et al., 2009, p. 379), it becomes clear why selection decision making is particularly susceptible to the insidious effects of nondiagnostic information. Specifically, selection decision makers want to use their intuitions when evaluating information about candidates, and, as described further later, the amount 
and accessibility of information, diagnostic and nondiagnostic, about job candidates is not only increasing rapidly, but its use is being embraced by selection decision makers.

Technological advances in the way selection decision are made have done little to help alleviate concerns regarding the influence of nondiagnostic information. Indeed, organizations are increasingly using technological tools like automated résumé screening, machine learning, and natural language processing of archival data and automatically scored video-based interviews to assess candidates (Horn $\&$ Behrend, 2017). Although on their surface these tools suggest that nondiagnostic information would be less likely to influence decisions, a common component of all of these tools is the need to develop and train a scoring algorithm (Raghavan \& Barocas, 2019). These algorithms need to be built by human decision makers and trained/calibrated on existing data. The biases inherent in human judgment and decision making, however, will impact the development of the algorithms (Vasconcelos et al., 2018), and the training data that most organizations have will be based on human judges' past work - these data, then, are also likely to show biases of human judgment and decision making, and can exacerbate the use of nondiagnostic information (Polli, 2019). These dual concerns were recently brought to light when it was discovered that Amazon's artificial intelligence résumé screening algorithm was biased against women (Dastin, 2018). The algorithm was built to screen for specific features of résumés related to successful performance in technology roles (dominated by male hires) and was then trained on 10 years' worth of Amazon résumés (dominated by male candidates); as a result of the structure of the algorithm and the bias in the training data, "Amazon's system taught itself that male candidates were preferable" (Dastin, 2018, n.p.).

As can be seen, the selection decision making landscape is quite susceptible to the negative influence of nondiagnostic information. Selection decision makers prefer to use their intuition when making decisions (Highhouse, 2008), but using one's intuition can result in an inadequate evaluation of the utility of information used to make a decision (Milkman et al., 2009; Soll et al., 2015). The outcome, then, is selection decisions being made without fully considering the appropriateness of the information being used resulting in biased (i.e., incorrect) selection decisions (Hastie \& Dawes, 2001). Whether the incorrect selection decision is a false positive or false negative, however, will depend on the decision made based on the nondiagnostic information: If nondiagnostic information is used to screen out applicants, then false negatives can result; if used to make a finalist choice, then false positives can result. Having outlined how nondiagnostic information impacts selection decisions, we now turn to the types of nondiagnostic information that selection decision makers can encounter.

\section{Types of Nondiagnostic Information}

As noted above, what makes information nondiagnostic is that it is not valid for the decision being made. In the case of selection decisions, nondiagnostic information refers to facts provided or learned that do not pertain to the job at hand, are not relevant for predicting job performance, and/or cannot be verified. Broadly, then, we distinguish between two types of nondiagnostic information: (a) verified information about a job candidate that is unrelated to work performance - therefore unrelated to the hiring decision, and (b) unverified information (i.e., the authenticity of the information is unknown) about a job candidate that may or may not be related to work performance.

In addition to being verified or not, candidate information can also be distinguished between legal or illegal ${ }^{4}$ for selection decision making. Table 1 provides the categories these two dimensions make and gives examples of types of information in each. Whereas the majority of nondiagnostic information available to selection decision makers falls in the verified group, information from the unverified group might be more troublesome for selection decision makers because this information is likely more compelling and increasing in availability as the use of social networking sites to recruit and select individuals increases (Dalal et al., 2015).

Verified but nondiagnostic. Information is verified if it has been explicitly confirmed or it is reasonable to assume that the information is accurate (e.g., inferring race from a picture). Although the latter part of the definition signals some ambiguity regarding the accuracy of the information, by and large, this information is likely to be accurate (Lewandowsky et al., 2012). Because information is accurate, though, does not mean it is helpful for making a decision. The aforementioned study by Rattan and colleagues (2019) demonstrated that the race and gender of an applicant affects hirability judgments - particularly when selecting for job for which stereotype information might be strong (e.g., software engineer). Other research has shown that job applicants can be discriminated against based on perceived religious affiliation (King \& Ahmad, 2010), weight (Pingitore et al., 1994), age (Carlsson \& Eriksson, 2019), and pregnancy status (Morgan et al., 2013). These studies show that not only do individuals use information that is unrelated to hiring decisions for most jobs, but they are willing to

\footnotetext{
4 We acknowledge that clearly labeling a piece of information as legal or illegal is not always feasible given the differences among employment laws across and within countries. In our presentation here, we focus on information that is illegal at the U.S. federal level (e.g., Title VII of the Civil Rights Act; American's with Disabilities Act) as of the year of publication. Many of these same classes of individuals are considered protected classes in other countries as well (e.g., Canada, United Kingdom, European Union countries).
} 
TABLE 1.

Categorization of Nondiagnostic Information Based on Verification and Legality for Use in Selection Decision Making

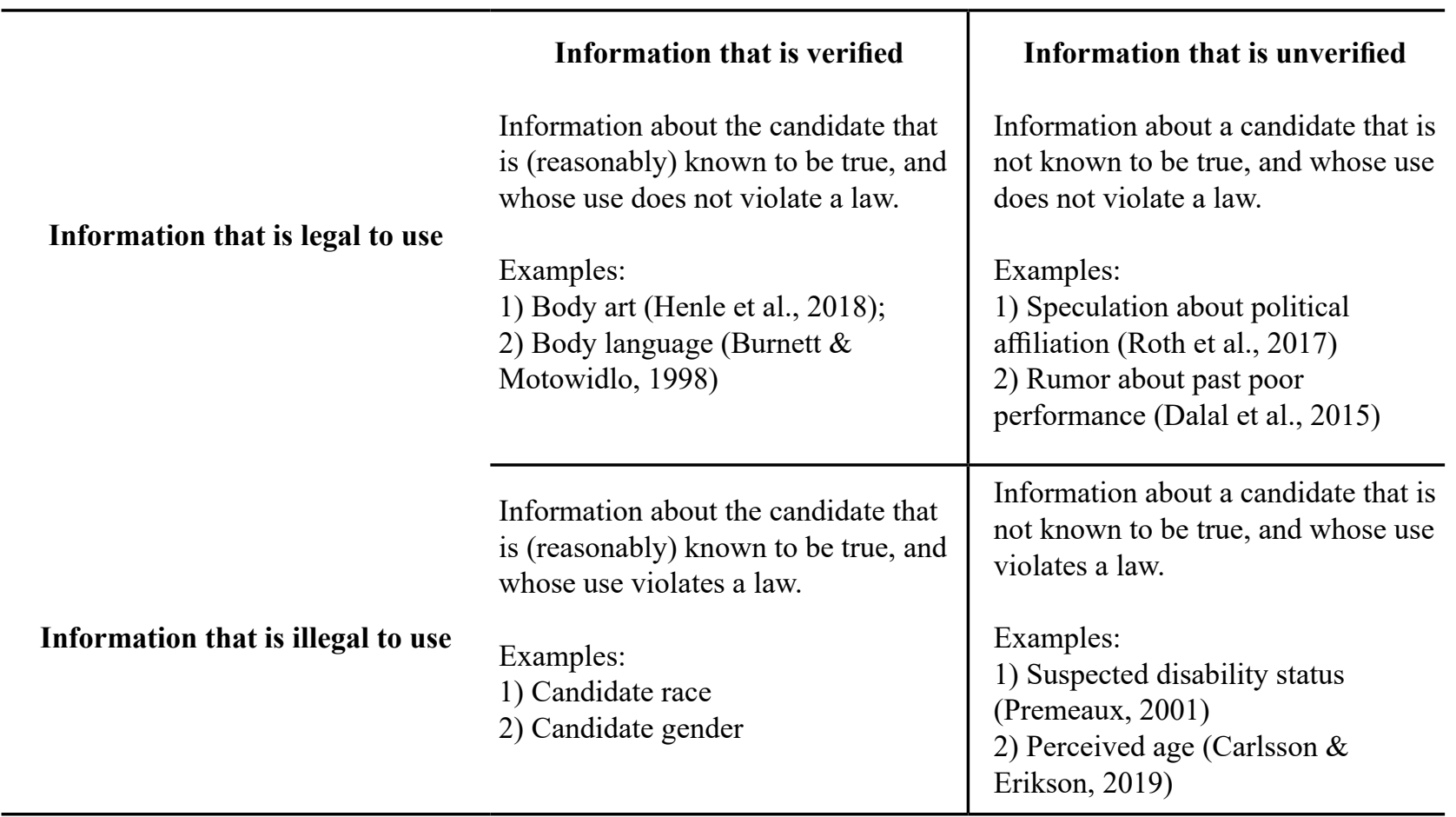

Note. Legality of information based on United States federal law as of the year 2020. Examples assumed to be not job related.

base decisions off information about protected classes (i.e., engage in illegal selection practice; SIOP, 2018).

In addition to these protected classes, selection decision makers may use some nondiagnostic information that, although not necessarily illegal, is unlikely to be predictive of future work performance. Examples include body art (Henle et al., 2018); attractiveness (Lee et al., 2018); simply having a profile picture on a social networking website (SNS), professional (i.e., LinkedIn; Roulin \& Levashina, 2019) or not (i.e., Facebook; Baert, 2018); and the nonverbal cues that decision makers infer when talking to candidates (Burnett \& Motowidlo, 1998). In all of these cases, researchers demonstrated that applicants with these features were treated differently than equivalent applicants without these features. This is true even though whether or not an applicant would be successful on the job is, for the most part, unrelated to any of these factors.

Using SNS to screen and select candidates deserves special attention given the volume of information that these website provide as well as its influence during the hiring process (e.g., McFarland \& Ployhart, 2015). To be sure, some SNS (e.g., LinkedIn) contain job relevant and valid information (see Roulin \& Levashina, 2019). Where this practice gets problematic, though, is when the use of SNS results in encountering nondiagnostic information that later influences decision making, of which, there is much (Roth et al., 2013). In short, not only do SNS directly present nondiagnostic information (e.g., the inclusion of a profile picture), they can also signal other nondiagnostic information (e.g., revealing gender, ethnicity, parental status) that may be used by decision makers during the hiring process.

Unverified and therefore nondiagnostic. Unverified information, also known as misinformation (Lewandowsky et al., 2012), is information that is either objectively false (e.g., millennials are lazy and have poor work ethic) or that has yet to be verified (e.g., hearsay; speculation). Both types of information are nondiagnostic because the information is, or could be, false. Thus, making decisions using these categories of information can bias decisions (e.g., not hiring a millennial candidate) by not only using a nondiagnostic piece of information but also possibly using information that is not true (Dalal et al., 2015; Lewandowsky et al., 2012). Importantly, ignoring unverified nondiagnostic information may result in more extreme judgments or less extreme judgments depending on the nature of the diagnostic and nondiagnostic information and the context of the decision.

Selection decision makers may also encounter rumors, "unverified, instrumentally relevant information statements transmitted among people," (p. 225, Dalal et al., 2015), about the candidates when engaging in Internet searches for candidate information (Davidson et al., 2011). Selection 
decision makers should discount whatever information is in a rumor; as such, their judgments should be formed only from the verified diagnostic information presented, meaning judgments should become either more or less extreme depending on the extremity of the rumored information relative to the diagnostic information. If the rumored information points to a more extreme judgment than the diagnostic information alone, actual judgments should be less extreme if the rumor is ignored, and vice versa.

Although one may question the extent to which rumors influence hiring judgments, Dalal and colleagues (2015) showed that working adults with hiring experience are influenced by rumors. These participants stated that rumored information, compared to non-rumored information, is less verified, less important, less helpful, and less useful when making judgments. Additionally, respondents also believed this information less and said they were less likely to use rumored information when making hiring decisions. Nevertheless, actual decisions made by the same individuals did not show evidence of discounting the rumored information. Individuals who received rumored information treated that information identically to those who received the same information but not as a rumor (i.e., as diagnostic for predicting work performance). Although decision makers stated they would not trust or use rumors to make hiring decisions, their actual judgments still utilized this information, even when they knew the information was a rumor. In addition to biasing judgments, use of such information can open organizations to negligent hiring and/or defamation lawsuits (see Ryan \& Lasek, 1991).

\section{Why Nondiagnostic Information Affects Decision Making}

Understanding the causal mechanisms by which nondiagnostic information impacts decision making can point to possible solutions. As noted earlier, selection decision makers' reliance on their intuitions can explain why they struggle to adequately evaluate the diagnosticity of the information and also why nondiagnostic information is so alluring to them (Highhouse, 2008; Milkman et al., 2009; Soll et al., 2015). Here, we explore the underlying processes by which the nondiagnostic information results in biased judgments; specifically, we outline two categories of explanations: (a) proposed underlying processes causing individuals to use nondiagnostic information, and (2) the impact of nondiagnostic information on other cognitive processes that hinder decision making.

Underlying causal processes. Nisbett and colleagues (1981) originally proposed that dilution occurs because individuals utilize a representativeness heuristic when forming judgments. Specifically, in judging the outcome of some social target, an individual will compare the number of common (e.g., score on a standardized test) and uncom- mon features (e.g., has a family) the target has relative to a representative exemplar in a category for the judgment (e.g., hirability judgments). The presence of nondiagnostic information introduces uncommon features between the target and the exemplar group, therein diluting judgments (i.e., a candidate with a family is outside the category domain, thus judged to have lower performance than the category of only standardized test information).

An alternative perspective on the causal mechanism for the dilution effect stems from conversational theory. According to this perspective, decision makers expect individuals to adhere to conversational maxims (Grice, 1975) such that people will only share information pertinent to the judgment at hand (maxims of relation), only share information known to be accurate or true (maximum of quality), and only contribute the information required for the exchange (maxim of quantity). As such, according to the conversational theory of dilution, decision makers use the nondiagnostic information because they expect the information to be relevant given the norms of conversation (Kemmelmeier, 2004),

Finally, a third perspective on the impact of nondiagnostic information on judgments is that of integrative complex thinking. Tetlock and Boettger (1989) showed that when provided with nondiagnostic information, individuals process information in such a way as to draw meaningful connections among different pieces of information. According to this perspective, nondiagnostic information impacts decision making because the presence of the information spurs the decision maker to engage in more complex thinking; this complex thinking in turn results in the decision maker using the information to make a decision that is less accurate than a decision using only the single piece of diagnostic information.

Other cognitive processes. Beyond these direct causal explanations, others have proposed that nondiagnostic information hindered decision making because its effects on other cognitive processes. First, Dana et al. (2013) proposed that decision makers engage in sensemaking when provided with nondiagnostic information (see Dalal et al., 2015 for how sensemaking can drive the use of rumors). That is, decision makers fit a coherent story to nondiagnostic information (i.e., unstructured interview responses) to justify their decision. Similarly, Kausel et al. (2016) proposed that the nondiagnostic information of an unstructured interview actually made decision makers overconfident in their judgments. Similar cognitive processes include the myth of expertise (Highhouse, 2008) wherein selection decision makers believe they have the expertise to glean meaningful information from nondiagnostic data and reach-around knowledge (Dunning, 2014) - information that is unrelated to a decision but that the decision maker uses to justify his/ her choice. Additionally, nondiagnostic information is likely to exacerbate confirmation bias, the tendency to seek in- 
formation that endorses people's preexisting beliefs (Zhang \& Highhouse, 2018). In all cases, the presence of the nondiagnostic information affects the decision maker's ability to ignore the nondiagnostic information.

Finally, accountability for a decision can exacerbate the impact of nondiagnostic information. Traditionally, holding decision makers accountable for their choices tends to reduce biased decision making (Tetlock \& Boettger, 1989). This is true, however, if the decision maker has only relevant information from which to make the decision; otherwise, accountability can increase the use of nondiagnostic information. Tetlock and Boettger (1989) demonstrated that judges under an accountability manipulation were more likely to utilize the nondiagnostic information (i.e., diluted their judgments). In short, accountability can actually make the impact of nondiagnostic information worse; unfortunately, selection decision makers are accountable for their choices suggesting that the impact of nondiagnostic information will be worse, not better, in these contexts (Zhang \& Highhouse, 2018).

\section{Prevalence of Verified and Unverified Nondiagnostic Information}

Although the preponderance of research shows that nondiagnostic information can negatively impact decision making, a natural follow-up question is: Do selection decision makers encounter nondiagnostic information when making hiring decisions? In this section, we present a picture of the prevalence of verified nondiagnostic information by reviewing the frequency with which selection decision makers utilize sources of this information. ${ }^{6}$ Then, we present the results of a large-scale workforce survey to gauge the prevalence of unverified nondiagnostic information.

Prevalence of verified nondiagnostic information. We can gain a sense of the prevalence of verified nondiagnostic information by looking at the rate with which selection decision makers utilize information sources likely to contain nondiagnostic information. First, one avenue by which decision makers may obtain nondiagnostic information is while interviewing a candidate, particularly when using an unstructured interview (Dana et al., 2013; Kausel et al., 2016). Interviewing candidates remains one of the most popular selection methods for the employer (Highhouse, 2008) and the candidate (Maurer, 2015). Supporting this view, a 2017 benchmarking survey of Society for Human Resource Management (SHRM) members found that $68 \%$ of organizations use one-on-one interviews at all levels of hiring, with up to $14 \%$ of them using an unstructured interview (SHRM, 2017).

Second, using SNS to screen applicants is growing in popularity to the point that some are suggesting online presence will be more important than a résumé (Schwabel, 2011). In a separate benchmarking survey, SHRM found that $70 \%$ of employers leverage SNS as a recruiting strat- egy (SHRM, 2016). Moreover, employers are increasingly using SNS to conduct background checks to confirm a candidate's qualifications for a position (Segal, 2018). Although some SNS may contain valid information about a candidate (e.g., LinkedIn; Roulin \& Levashina, 2019), others do not (Roth et al., 2013). To this latter point, $22 \%$ of respondents reported using more questionable SNSs such as Facebook or Instagram to research job candidates (Segal, 2018). Indeed, Roth and colleagues (2013) note that, " $75 \%$ of recruiters are required to do online research of applicants, and $70 \%$ reported rejecting individuals as a result" (p. 2).

Finally, selection decision makers are increasingly utilizing their referral networks to obtain information about candidates (Ryan, 2015). These formal, in the form of letters of recommendation, and informal conversations will likely be a mix of diagnostic, verified nondiagnostic, and potentially unverified information. Letters of recommendation/referral may be particularly tricky insofar as individuals may perceive information as diagnostic and/ or verified based on the letter writer's perceived credibility (Lewandowsky et al., 2012). In short, selection decision makers, relying on their intuition, may insufficiently vet the credibility of the source and/or information in a letter of recommendation, opting to believe the information because the source is assumed credible (Milkman et al., 2009). In sum, a large proportion of selection decision makers are utilizing information sources likely to contain a mix of diagnostic and nondiagnostic information; given that decision makers find it difficult to ignore nondiagnostic information, these prevalence estimates are concerning.

Prevalence of unverified information. Although it is possible that selection decision makers may encounter unverified information through their Internet searches of job candidates, it is important to demonstrate the prevalence of this type of information more directly. To that end, we analyzed archival data collected as part of a large-scale survey conducted by IBM. ${ }^{7}$

\section{Participants and Procedures}

In 2016, 7,735 respondents participated in a large-scale survey, known as the WorkTrends Survey, administered by the IBM Smarter Workforce Institute. The participants were on average 37 years old $(S D=10.34), 58 \%$ male, $55 \%$ mid-level managers, and $74 \%$ had bachelor's or graduate degrees. Importantly, all of these respondents had been personally responsible for hiring new employees within the year of the survey. Among other questions asked, participants were asked "how often have you heard a rumor (e.g., from a colleague, social media sites, etc.) about a job appli-

6 We acknowledge that these sources of information are likely to contribute diagnostic information as well. Our focus on nondiagnostic information is to keep in line with the message of our paper.

7 This is the first time these data have been published in any format. 
cant during the selection process" on a 5-point scale (1 = "never"; 5 = "always").

\section{Results and Discussion}

Sixty-five percent of the participants reported "sometimes", "often", or "always" $(31 \%, 25 \%$, and $9 \%$, respectively) encountering a rumor about a job candidate during the selection process, with less than $15 \%$ of the participants saying they have "never" heard a rumor about a candidate. As can be seen, this direct question to selection decision makers shows that the majority of individuals are encountering rumors. These results coupled with those of Dalal and colleagues (2015) paint a potentially troubling picture: Selection decision makers are hearing rumors about candidates, and they may not be ignoring them when making decisions. This is true even though this information has no validity for making selection decisions (at least until verified which is rare, Dalal et al., 2015).

\section{Mitigation Strategies}

The inability to ignore plainly nondiagnostic information when forming judgment can result in suboptimal selection decisions (Highhouse, 1997). Beyond hindering decision quality, though, using nondiagnostic information when making selection decision can potentially result in adverse impact. For example, decision makers who used their intuitions to form holistic judgments of candidates' LinkedIn profiles showed a trend toward adverse impact in their decision making (Roulin \& Levashina, 2019). In addition, a growing concern is organizations discriminating against those with family responsibilities during the hiring process (i.e., family responsibilities discrimination [FRD]; Albiston et al., 2007). Given the ease with which employers can learn about the family status of job candidates with Internet and SNS information (e.g., family photos; group affiliations), concerns of FRD are increasing. When coupled with the negative impacts perceived ethnicity, gender (Rattan et al., 2019), religious affiliation (King \& Ahmad, 2010), age (Carlsson \& Eriksson, 2019), and pregnancy status (Morgan et al., 2013), among others, have on hiring decisions, the use of nondiagnostic information in selection decision making can lead to adverse impact.

In light of these negative implications, we conclude by offering suggestions for mitigating the impact of nondiagnostic information in selection decision making. Although an obvious solution is to avoid being presented nondiagnostic information, it is nearly impossible to avoid nondiagnostic information. Instead, we organize our review of mitigation strategies around debiasing techniques (Larrick, 2004; Milkman et al., 2009; Soll et al., 2015). With respect to debiasing the use of nondiagnostic information, we will consider debiasing the process by which decision-making procedures are corrected for systematic deficiencies in the use of information. ${ }^{8}$ Furthermore, biases can be attributed to either the person or the task. In the former, the decision environment is considered fixed, and the decision maker must be given training, knowledge, or tools to overcome the bias.

In the latter, the decision context is changed to better match the person making the decision. Soll and colleagues (2015) refer to these two categories of debiasing as "modify the decision maker" and "modify the environment," respectively (p. 926); we provide examples within each domain.

\section{Modify the Decision Maker}

The best performing, yet least used, modification to the decision maker is to standardized the collection of valid information and statistically combine this data. Indeed, by removing human intuition from collecting and combining data, nondiagnostic information cannot influence the decision. In the case of selection decision making, this would entail using standardized pre-employment screening methods (e.g., structured interviews, paper-and-pencil tests of psychological constructs), and combining these data using simple linear equations, which have been shown to outperform human judges (Dawes et al., 1989). However, previous research has found that selection decision makers react negatively to standardized preemployment assessments and algorithmic combination of data (e.g., Highhouse, 2008; Nolan et al., 2016; Nolan et al., 2020). In addition, some standardized assessment methods may still provide avenues for nondiagnostic information to influence judgments as in the case of initial impressions developed during rapport building phases of structured interviews (see Swider et al., 2016). Despite these concerns, the validity of structure selection systems has been demonstrated repeatedly and is perhaps one of the best ways to limit the impact of nondiagnostic information on selection decision making (Highhouse, 2008); as such, selection decision makers should continue to be advised to consider such approaches.

Another modification that could be made is to train selection decision makers on the rules for making unbiased judgments (Larrick, 2004) such as training on recognizing and avoiding nondiagnostic information. We note here that in some instances the biases exhibited by a selection decision maker might be implicit, so training these biases may be more difficult than others. However, this training could take the form of cognitive feedback: information about what cues decision makers are using to make decisions relative to which cues are valid for making decisions (Balzer et al., 1989). Providing decision makers with a glimpse into how

8 Debiasing decision procedures is different from addressing coherence-based and correspondence-based biases. Whereas the former category involves biases resulting from logical inconsistencies, the latter category involves biases resulting from misperceptions of reality. See Soll, Milkman, and Payne (2015) for a detailed discussion of these three categories of biases. 
they are using diagnostic and nondiagnostic information to make their decisions can help them learn what information to ignore before forming their judgment (see also, D. K. Dalal et al., 2010). Indeed, individuals who cross out nondiagnostic information before making a judgment showed reduced dilution (Kemmelmeier, 2004).

The final decision-maker modification we discuss is the "consider the opposite" technique. In this debiasing strategy, the decision maker is asked to consider the opposing choice (e.g., another job finalist) or consider reasons why the initial choice might be wrong. The goal of this technique is to mitigate a narrow focus on confirming evidence (Larrick, 2004; Soll et al., 2015; Zhang \& Highhouse, 2018). In the case of selection decision making, this technique might encourage the decision maker to consider how and why the used the information provided to them, and identify reasons why a decision based on nondiagnostic information might be wrong.

\section{Modify the Decision Environment}

The second path to mitigating the use of nondiagnostic information in selection decision making is to modify the decision context in which the decision is being made. In this case, the goal is not necessarily to change the decision maker but to change the decision environment to reduce bias. One such approach is to formalize the rules by which information can be used which has been shown to reduce the reliance on nondiagnostic information (Waller \& Zimbelman, 2003). By giving decision makers specific instructions on how to use different sources of information, they are less likely to rely on their intuition and therein rely less on nondiagnostic information. For example, Roulin and Levashina (2019) applied this rule to using SNS information and showed that formalizing the procedures by which selection decision makers use LinkedIn reduced the potential for adverse impact and resulted in the use of more valid LinkedIn information (i.e., better use of diagnostic information).

A second decision environment change is to use planning prompts (Soll et al., 2015). Planning prompts require that an individual decide on, among other things, how to make a decision. These plans can then be checked to ensure that nondiagnostic information is not intended to be used, and form a "commitment that is both psychologically difficult to break and memorable" (p. 937, Soll et al., 2015). In this way, planning prompts commit the selection decision maker to a strategy that removes the use of nondiagnostic information.

Table 2 summarizes the main takeaway points from this paper. That nondiagnostic information can negatively affect selection decisions is not new, yet the impact of this infor

\section{TABLE 2.}

\section{Takeaway Points From the Current Article}

\footnotetext{
1. Nondiagnostic information is information that is not related to the decision being made, and its use would result in worse quality decisions.
}

2. We distinguish two types of nondiagnostic information:

a) verified information about a candidate that is unrelated to work performance (e.g., gender).

b) unverified information about a candidate that, because the veracity of the information is unknown, may or may not be related to work performance (e.g., rumors).

3. Nondiagnostic information comes from many sources; sources that are popular among selection decision makers (e.g., LinkedIn) and/or can be trained into technology (e.g., gender bias in automated resume screening.

4. Nondiagnostic information is particularly alluring for decision makers who believe their expertise can improve selection decisions. This is because the addition of nondiagnostic information increases perceived confidence but a decrease in accuracy.

5. Using nondiagnostic information can open up organizations to potential claims of adverse impact.

6. Selection practitioners should limit the use of nondiagnostic information by engaging in debiasing techniques:

a) Modifying the decision maker such as using structured selection systems, engaging in cognitive feedback training, or using "consider the opposite" prompts.

b) Modifying the decision environments such as setting rules for what information is allowable in selection decisions and how, or using planning prompts.

7. Organizations should provide resources and/or implement processes that can help curb the use of nondiagnostic information among its selection decision makers.

a) Provide continuous debiasing training to their selection decision makers.

b) Consider providing debiasing training to all employees given the increase in employee referrals practices and team hiring practices within organizations. 
mation is not abating. Recognizing the inappropriateness of nondiagnostic information is just the first step to eliminating the impact. The strategies presented here represent just a sample of different approaches available to selection decision makers. Using these strategies should mitigate the deleterious influence of nondiagnostic information on selection decisions during the selection process.

\section{REFERENCES}

Albiston, C., Dickson, K. B., Fishman, C., \& Levy, L. F. (2007). Ten lessons for practitioners about family responsibilities discrimination and stereotyping evidence. Hastings Law Journal, 59, 1285-1310.

Baert, S. (2018). Facebook profile picture appearance affects recruiters' first hiring decisions. New Media \& Society, 20, 1220-1239.

Balzer, W. K., Doherty, M. E., \& O'Connor, R., Jr. (1989). Effects of cognitive feedback on performance. Psychological Bulletin, 106, 410-433.

Brown, V. R. \& Vaughn, E. D. (2011). The writing on the (Facebook) wall: The use of social networking sites in hiring decisions. Journal of Business and Psychology, 26, 219.

Burnett, J. R., \& Motowidlo, S. J. (1998). Relations between different sources of information in the structured selection interview. Personnel Psychology, 51, 963-983.

Camerer, C. F., \& Johnson, E. J. (1991). The process-performance paradox in expert judgment: How can experts know so much and predict so badly? In K. A. Ericsson \& J. Smith (Eds.), Toward a general theory of expertise: Prospects and limits (pp. 195-217). Cambridge, UK: Cambridge University Press.

Carlsson, M., \& Eriksson, S. (2019). Age discrimination in hiring decisions: Evidence from a field experiment in the labor market. Labour Economics, 59, 173-183.

Carr, C. T., Hall, R. D., Mason, A. J., \& Varney, E. J. (2017). Cueing employability in the gig economy: Effects of task-relevant and task-irrelevant information on Fiverr. Management Communication Quarterly, 31, 409-428.

Dalal, D. K., Diab, D. L., Balzer, W. K., \& Doherty, M. E. (2010). The lens model: An application of JDM methodologies to IOOB practice. Industrial and Organizational Psychology: Perspectives on Science and Practice, 3, 424-428.

Dalal, D. K., Diab, D. L., \& Tindale, R. S. (2015). I heard that...: Do rumors affect hiring decisions? International Journal of Selection and Assessment, 23, 224-236.

Dalal, R. S., Bonaccio, S., Highhouse, S., Ilgen, D. R., Mohammed, S., \& Slaughter, J. E. (2010). What if industrial-organizational psychology decided to take workplace decisions seriously? Industrial and Organizational Psychology: Perspectives on Science and Practice, , 3, 386-405.

Dana, J., Dawes, R., \& Peterson, N. (2013). Belief in the unstructured interview: The persistence of an illusion. Judgment and Decision Making, 8, 512-520.

Dastin, J. (2018, October 9). Amazon scarps secret Al recruiting tool that showed bias against women. Reuters. Retrieved February 25, 2020 from: https://www.reuters.com/article/ us-amazon-com-jobs-automation-insight/amazon-scrapssecret-ai-recruiting-tool-that-showed-bias-against-womenidUSKCN1MK08G
Davidson, H. K., Maraist, C., \& Bing, M. N. (2011). Friend or foe? The promise and pitfalls of using social networking sites for HR decisions. Journal of Business and Psychology, 2, 153159.

Dawes, R. M., Faust, D., \& Meehl, P. E. (1989). Clinical versus actuarial judgment. Science, 243, 1668-1774.

Dunning, D. (2014). The problem of recognizing one's own incompetence: Implications for self-assessment and development in the workplace. In S. E. Highhouse, R. S. Dalal, \& E. Salas (Eds.), Judgment and decision making at work (pp. 3756). New York, NY: Routledge.

Fatemi, F. (2016, September). The true cost of a bad hireit's more than you think. Forbes. Retrieved February 25, 2020 from https://www.forbes.com/sites/falonfatemi/2016/09/28/the-true-cost-of-a-bad-hire-its-morethan-you-think/\#3b4219904aa4

Grice, H. P. (1975). Logic and conversation. In P. Cole, \& J. L. Morgan (Eds.), Syntax and semantics: Speech acts (Vol. 3, pp. 41-58). New York, NY: Academic Press.

Hammond, K. R. (1955). Probabilistic functionalism and the clinical method. Psychological Review, 62, 255-262.

Hastie, R., \& Dawes, R. M. (2001). Rational choice in an uncertain world (2nd edition). Thousand Oaks, CA: SAGE.

Henle, C. A., Shore, T. H., \& Marshall, A. (2018). Body art as a source of employment discrimination. Academy of Management Proceedings, 2018.

Highhouse, S. (1997). Understanding and improving job-finalist choice: The relevance of behavioral decision research. Human Resource Management Review, 7, 449-470.

Highhouse, S. (2008). Stubborn reliance on intuition and subjectivity in employee selection. Industrial and Organizational Psychology: Perspectives on Science and Practice, 1, 333342.

Horn, R. G., \& Behrend, T. S. (2017). Video killed the interview star: Does picture-in-picture affect interview performance? Personnel Assessment and Decisions, 3, 51-59.

Kausel, E. E., Culbertson, S. S., \& Madrid, H. P. (2016). Overconfidence in personnel selection: When and why unstructured interview information can hurt hiring decisions. Organizational Behavior and Human Decision Processes, 137, 27-44.

Kemmelmeier, M. (2004). Separating the wheat from the chaff: Does discriminating between diagnostic and nondiagnostic information eliminate the dilution effect? Journal of Behavioral Decision Making, 17, 231-243.

King, E. B., \& Ahmad, A. S. (2010). An experimental field study of interpersonal discrimination toward Muslim job applicants. Personnel Psychology, 63, 881-906.

Larrick, R. P. (2004). Debiasing. In D.J. Koehler \& N. Harvey (Eds.), Blackwell handbook of judgment and decision making (pp. 316-337). Malden, MA: Blackwell.

Lee, M., Pitesa, M., Pillutla, M. M., \& Thau, S. (2018). Perceived entitlement causes discrimination against attractive job candidates in the domain of relatively less desirable jobs. Journal of Personality and Social Psychology, 114, 422-442.

Lewandowsky, S., Ecker, U. K. H., Seifert, C. M., Schwarz, N., \& Cook, J. (2012). Misinformation and its correction: Continued influence and successful debiasing. Psychological Science in the Public Interest, 13, 106-131.

Maurer, R. (2015, July 27). Interview most critical part of hiring process, candidates say. Retrieved May 24, 2019 from: https://www.shrm.org/ResourcesAndTools/hr-topics/tal- 
ent-acquisition/Pages/Interview-Critical-Hiring-Process. aspx\#sthash.wbRRDEqg.dpuf

McFarland, L. A., \& Ployhart, R. E. (2015). Social media: A contextual framework to guide research and practice. Journal of Applied Psychology, 100, 1653-1677.

Milkman, K. L., Chugh, D., \& Bazerman, M. H. (2009). How can decision making be improved? Perspectives on Psychological Science, 4, 379-383.

Morgan, W. B., Walker, S. S., Hebl, M. R., King, E B. (2013). A field experiment: Reducing interpersonal discrimination toward pregnant job applicants. Journal of Applied Psychology, 98, 799-809.

Nisbett, R. E., Zukier, H., \& Lemley, R. E. (1981). The dilution effect: Nondiagnostic information weakens the implications of diagnostic information. Cognitive Psychology, 13, 248-277.

Nolan, K. P., Carter, N. T., \& Dalal, D. K. (2016). Threat of technological unemployment: Are hiring managers discounted for using standardized employee selection practices? Personnel Assessment and Decisions, 2, 30-47.

Nolan, K. P., Dalal, D. K., \& Carter, N. T. (2020). Threat of technological unemployment, use intentions, and the promotion of structured interviews in personnel selection. Personnel Assessment and Decisions, 6(2), 38-53.

Northon, L. (lead), Dooney, J., Esen, E., Kong, W., \& Marriotti, A. (contributors) (2016). 2016 human capital report. SHRM: Alexandria, VA.

Pingitore, R., Dugoni, B. L., Tindale, R. S., \& Spring, B. (1994). Bias against overweight job applicants in a simulated employment interview. Journal of Applied Psychology, 79, 909-917.

Polli, F. (2019, October, 29). Using Al to eliminate bias from hiring. Harvard Business Review. Retrieved February 25, 2020 from: https://hbr.org/2019/10/using-ai-to-eliminate-biasfrom-hiring

Premeaux, S. F. (2001). Impact of applicant disability on selection: The role of disability type, physical attractiveness, and proximity. Journal of Business and Psychology, 16, 291-298.

Raghavan, M., \& Barocas, S. (2019, December 6). Challenges for mitigating bias in algorithmic hiring. Brookings. Retrieved February 25, 2020 from: https://www.brookings.edu/research/challenges-for-mitigating-bias-in-algorithmic-hiring/

Rattan, A., Steele, J., Ambady, N. (2019). Identical applicant but different outcomes: The impact of gender versus race salience in hiring. Group Processes \& Intergroup Relations, 22, 80-97.

Roth, P. L., Bobko, P., Van Iddekinge, C. H., \& Thatcher, J. B. (2013). Social media in employee selection-related decisions: A research agenda for uncharted territory. Journal of Management, 20, 1-30.

Roulin, N., \& Bangerter, A. (2013). Social networking websites in personnel selection. Journal of Personnel Psychology, 12, 143-151.

Roulin, N., \& Levashina, J. (2019). Linkedln as a new selection method: Psychometric properties and assessment approach. Personnel Psychology, 72, 187-211.

Ryan, A. M., \& Lasek, M. (1991). Negligent hiring and defamation: Areas of liability related to pre-employment inquiries. Personnel Psychology, 44, 293-319.

Ryan, L. (2015, January 23). The truth about employee referrals. Forbes. Retrieved from https://www.forbes.com/sites/ lizryan/2015/01/23/the-truth-about-employee-refer- rals/\#47c4ef354383

Schwabel, D. (2011, February 21). 5 reasons why your online presence will replace your resume in 10 years. Forbes. Retrieved February 25, 2020 from: www.forbes.com/sites/ danschawbel/2011/02/21/5-reasons-why-your-online-presence-will-replace-your-resume-in-10-years/

Segal, J. A. (2018, April 11). Social media use in hiring: Assessing the risks. HR Magazine, 59. Retrieved from https://www. shrm.org/hr-today/news/hr-magazine/pages/0914-social-media-hiring.aspx

SHRM (2016). The new talent landscape: Recruiting difficulty and skills shortages. Alexandria, VA: Society for Human Resource Management.

SHRM (2017, December). 2017 talent acquisition benchmarking report. Retrieved from https://www.shrm.org/hr-today/ trends-and-forecasting/research-and-surveys/documents/2017-talent-acquisition-benchmarking.pdf.

SIOP (2018). Principles for the validation and use of personnel selection procedures (5th Edition). Bowling Green, $\mathrm{OH}$ : Society for Industrial and Organizational Psychology.

Soll, J. B., Milkman, K. L., \& Payne, J. W. (2015). The user's guide to debiasing. In G. Keren \& G. Wu (Eds.), The Wiley Blackwell handbook of judgment and decision making (pp. 924-951). Malden, MA: John Wiley \& Sons.

Sprague, R. (2007). Googling job applicants: Incorporating personal information into hiring decisions. Labor Lawyer, 23, 19-40.

Swider, B. W., Barrick, M. R., \& Harris, T. B. (2016). Initial impressions: What they are, what they are not, and how they influence structured interview outcomes. Journal of Applied Psychology, 101, 625-638.

Tetlock, P. E., \& Boettger, R. (1989). Accountability: A social magnifier of the dilution effect. Journal of Personality and Social Psychology, 57, 388-398.

Troutman, C. M., \& Shanteau, J. (1977). Inferences based on nondiagnostic information. Organizational Behavior and Human Performance, 19, 43-55.

Vasconcelos, M., Cardonha, C., \& Goncalves, B. (2018). Modeling epistemological principles for bias mitigation in Al systems: An illustration in hiring decisions. Proceedings of the 2018 AAAI/ACM Conference on Al, Ethics, and Society, pp. 323329.

Waller, W. S., \& Zimbelman, M. F. (2003). A cognitive footprint in archival data: Generalizing the dilution effect from laboratory to field settings. Organizational Behavior and Human Decision Processes, 91, 254-268.

Zhang, D. C., \& Highhouse, S. (2018). Judgment and decision making in the workplace. In D. S. Ones, N. Anderson, C. Viswesvaran, \& H. K. Sinangil (Eds.), The SAGE handbook of industrial, work, and organizational psychology (vol 1., pp. 611-633). Thousand Oaks, CA: SAGE.

Zukier, H. (1982). The dilution effect: The role of the correlation and the dispersion of predictor variables in the use of nondiagnostic information. Journal of Personality and Social Psychology, 43, 1163-1174.

RECEIVED 09/09/19 ACCEPTED 04/21/20 